\title{
Suppression of Cold Weather Events over High-Latitude Continents in Warm Climates
}

\author{
ZEYUAN HU \\ Department of Earth and Planetary Sciences, Harvard University, Cambridge, Massachusetts \\ TIMOTHY W. CRONIN \\ Department of Earth, Atmospheric, and Planetary Sciences, Massachusetts Institute of Technology, Cambridge, Massachusetts \\ ELI TZIPERMAN \\ Department of Earth and Planetary Sciences, and School of Engineering and Applied Sciences, \\ Harvard University, Cambridge, Massachusetts
}

(Manuscript received 4 March 2018, in final form 27 September 2018)

\begin{abstract}
Recent studies, using Lagrangian single-column atmospheric models, have proposed that in warmer climates more low clouds would form as maritime air masses advect into Northern Hemisphere high-latitude continental interiors during winter (DJF). This increase in low cloud amount and optical thickness could reduce surface radiative cooling and suppress Arctic air formation events, partly explaining both the warm winter high-latitude continental interior climate and frost-intolerant species found there during the Eocene and the positive lapserate feedback in future Arctic climate change scenarios. Here the authors examine the robustness of this lowcloud mechanism in a three-dimensional atmospheric model that includes large-scale dynamics. Different warming scenarios are simulated under prescribed $\mathrm{CO}_{2}$ and sea surface temperature, and the sensitivity of winter temperatures and clouds over high-latitude continental interior to mid- and high-latitude sea surface temperatures is examined. Model results show that winter 2-m temperatures on extreme cold days increase about $50 \%$ faster than the winter mean temperatures and the prescribed SST. Low cloud fraction and surface longwave cloud radiative forcing also increase in both the winter mean state and on extreme cold days, consistent with previous Lagrangian air-mass studies, but with cloud fraction increasing for different reasons than proposed by previous work. At high latitudes, the cloud longwave warming effect dominates the shortwave cooling effect, and the net cloud radiative forcing at the surface tends to warm high-latitude land but cool midlatitude land. This could contribute to the reduced meridional temperature gradient in warmer climates and help explain the greater warming of winter cold extremes relative to winter mean temperatures.
\end{abstract}

\section{Introduction}

High-latitude continental interior winters were significantly warmer during the Eocene (56-33.9 million years ago) than at present, with frost-intolerant flora and fauna existing north of $50^{\circ} \mathrm{N}$ in North America (e.g., Wing and Greenwood 1993; Greenwood and Wing 1995; Markwick 1998). During that period, reconstructed temperatures show a much weaker meridional temperature gradient and a smaller seasonality over high latitudes (Greenwood and Wing 1995). Climate models have difficulties simulating such high-latitude continental warm

Corresponding author: Zeyuan Hu, zeyuan_hu@fas.harvard.edu winters while maintaining the tropical temperature consistent with proxy evidence without raising the partial pressure of $\mathrm{CO}_{2}\left(\mathrm{CO}_{2}\right)$ to very high values (Huber and Caballero 2011). Many mechanisms have been proposed to explain this equable climate problem, including polar stratospheric clouds [e.g., Sloan et al. 1992; Kirk-Davidoff et al. 2002; however, the suggested stratospheric feedback was disputed by Korty and Emanuel (2007)], dramatic expansion of the Hadley circulation (Farrell 1990; yet to be tested in a comprehensive model), increased poleward ocean heat transport due to ocean mixing by stronger tropical cyclones [Emanuel 2002; however, the highlatitude temperature response was found to be small by Korty et al. (2008)], and a convective cloud feedback 
(Abbot and Tziperman 2008a,b; Abbot et al. 2009b; Abbot and Tziperman 2009; Arnold et al. 2014). The convective cloud feedback has been verified by multiple models of different complexities and can explain the warmth of the Arctic Ocean, yet it cannot directly explain the warmth over continental interior land surfaces where sustained winter convection is not expected to occur. The Arctic and high-latitude continents are projected to warm much faster than the low latitudes [although Cohen et al. (2014) show a warming trend from 1960 to 2013 but a cooling trend from 1990 to 2013], particularly in winter (e.g., Screen and Simmonds 2010). The need to both understand past equable climates and to predict future climate change requires a better understanding of the mechanisms underlying winter warmth of continental interiors.

Climate models in the long-term projected future climate scenarios in phase 5 of the Coupled Model Intercomparison Project (CMIP5; Collins et al. 2013) generally predict a larger surface warming over high latitudes, especially in winter, and a maximum zonally averaged warming in the tropical upper troposphere and polar lower troposphere. Mechanisms for Arctic amplification of warming in climate models include both local positive feedbacks and nonlocal increases in moist static energy transport (e.g., Alexeev and Jackson 2013). Pithan and Mauritsen (2014) found that lapse-rate changes contribute more to Arctic amplification than does the surface albedo feedback, but the controls on the high-latitude lapse rate feedback remain incompletely understood. Cronin and Tziperman (2015) performed a single-column model study, treating Arctic air formation from a Lagrangian perspective by following a column of air moving from the ocean to over highlatitude continent during winter, following Curry (1983). They suggested that the surface-amplified Arctic warming and the related high-latitude lapse rate response occur primarily because of increasing optical thickness and low-cloud fractional cover, which effectively suppresses surface radiative cooling. This idea connects with observations of the Arctic winter boundary layer, which show two preferred states: low clouds accompanied by a relatively warm surface and weak surface inversion, and clear skies accompanied by a cold surface and a strong surface inversion (Stramler et al. 2011). The work by Cronin and Tziperman (2015), as well as a follow-up study with a two-dimensional cloud-resolving model by Cronin et al. (2017), suggests that the warm and cloudy boundary layer state may become more frequent in a warmer climate. Although such Lagrangian air-mass column studies are extremely idealized, Abbot et al. (2009a) also studied the Eocene climate in a general circulation model (GCM) and noted a significant increase of low cloud cover over highlatitude continental interior in a much warmer climate.
Long-term projections by CMIP5 climate models generally show that extreme cold events in Northern Hemisphere high latitudes decrease in a warmer climate (Collins et al. 2013), especially in the representative concentration pathway (RCP) 8.5 scenario (a businessas-usual scenario; e.g., van Vuuren et al. 2011). The reduced risk can be interpreted as less frequent extremely cold days (Screen et al. 2015), shorter duration of cold air outbreaks (Gao et al. 2015), and warmer extreme values of daily minimum temperature (Screen et al. 2015). The reduced frequency of extreme cold events can be largely explained by the increase of mean surface air temperature, but the decrease of the winter temperature variance over high latitudes also contributes significantly (Gao et al. 2015). The decreased winter temperature variance is a result of several processes, including the reduced meridional temperature gradient that occurs in tandem with Arctic amplification (Screen 2014; Schneider et al. 2015). Changes in the character or distribution of blocking events, and changes in snow cover, may also contribute to the change in the frequency of extreme cold events (Gao et al. 2015; Vavrus et al. 2006).

This paper attempts to link changes in extreme cold events in Northern Hemisphere high latitudes together with the low-cloud mechanism of surface-amplified Arctic warming described by the above-mentioned air-column Lagrangian model studies (Cronin and Tziperman 2015; Cronin et al. 2017). Following up on the work of Cronin and Tziperman (2015) and Cronin et al. (2017), which tested the dependence of Arctic air formation to the initial temperature and humidity profiles of a maritime air column, this paper examines the dependence of winter continental interior temperatures on mid- to high-latitude sea surface temperatures and sea ice extent in a three-dimensional atmospheric GCM. We run the Community Atmosphere Model with prescribed sea surface temperature (SST) and sea ice properties, specifying different levels of increased SST and examining the resulting continental climate, focusing on the distribution of winter temperatures, and particularly cold extremes. We consider some extreme warming scenarios in order to understand the processes involved, rather than limiting the study to realistic scenarios. In warmer climates, we find a significant increase of low-level clouds and longwave cloud radiative forcing at the surface, both in the winter mean state and on extreme cold days. The paper is organized as follows: section 2 describes the model and experiments, and section 3 describes and discusses the results and is subdivided into sections on temperature changes (section 3a), cloud changes (section $3 b$ ), and the general context of surface energy balance changes (section $3 \mathrm{c}$ ). We 
summarize our findings and discuss limitations of our study in section 4 .

\section{Model and experiment description}

The atmospheric model used here is the Community Atmosphere Model, version 4 (CAM4; Neale et al. 2010 ), with a horizontal resolution of $1.9^{\circ}$ (latitude) $\times$ $2.5^{\circ}$ (longitude) and 26 vertical levels. In our simulations, CAM4 is coupled to an active land model, the Community Land Model, version 4 (CLM4; Lawrence et al. 2011), and to a sea ice model, the Community Ice Code, version 4 (CICE4; Hunke and Lipscomb 2008). CICE is run in a thermodynamic-only mode in which sea ice thickness, sea ice fraction, and sea surface temperature are prescribed, and the model is used to calculate the ice surface temperature and fluxes.

To prescribe different warming scenarios, we choose 11 different boundary conditions with different SST and sea ice fraction distributions. For each simulation, we run 22 years and analyze the last 20 years. First, we conduct a control run with seasonal preindustrial SST and sea ice distributions. The preindustrial carbon dioxide concentration is set to $280 \mathrm{ppm}$. Next, we pick six periods from the Community Climate System Model, version 4 (CCSM4; Gent et al. 2011), RCP8.5 simulation and from the corresponding extension concentration pathway (ECP) simulation (ECP8.5; Riahi et al. 2007) in the CMIP5 dataset, namely 2006-15, 2041-60, 2081-2100, 2121-40, 2181-2200, and 22812300 , and we calculate the seasonal cycle of SST and sea ice fraction for our experiments from these periods. The carbon dioxide concentration in these periods is set to $390,550,850,1230,1770$, and $1960 \mathrm{ppm}$, respectively, while the concentration of other greenhouse gases is set to preindustrial values. Finally, to simulate even warmer scenarios, we set the sea ice cover to be zero everywhere for all seasons and impose different minimum SST values of $5^{\circ}, 10^{\circ}, 15^{\circ}$, and $20^{\circ} \mathrm{C}$ on the SST field from years 2281 to 2300 in the ECP8.5 simulation. In these warmer experiments, the carbon dioxide concentration is set to $1960 \mathrm{ppm}$, as at the end of ECP8.5. The objective of this final set of boundary conditions is to examine the effect of an extreme scenario of a reduced equator-topole surface temperature gradient on high-latitude continental interior winter temperatures.

In some of the analyses and discussion below, we focus in particular on four representative experiments to illustrate the change of forcing and range of responses: the preindustrial run (PI), the RCP8.5 2081-2100 run (RCP2090), the ECP8.5 2281-2300 run (ECP2290), and the run with greatest minimum SST value of $20^{\circ} \mathrm{C}$ $(\mathrm{SSTn}=20)$. To provide a single scalar metric of ocean warming, we define the "forcing temperature" as the average DJF surface temperature over ocean and sea ice (sea ice exists only in PI, RCP2090, and ECP2290) north of $45^{\circ} \mathrm{N}$.

\section{Results and discussion}

\section{a. Temperature patterns and extremes}

Surface temperatures over oceans and sea ice cover adjacent to the northern landmasses-both of which serve as important parts of the forcing of cold air events in high-latitude continental interiors-change dramatically from our coldest experiment (PI) to the warmest experiment $(\mathrm{SSTn}=20)$ as shown in Fig. 1 . In the PI experiment (Fig. 1a), winter (DJF) mean surface temperatures over the ice-covered Arctic region reach below $-35^{\circ} \mathrm{C}$, and the forcing temperature (surface temperature averaged over ocean and sea ice north of $45^{\circ} \mathrm{N}$ ) is $-9^{\circ} \mathrm{C}$. In the RCP2090 experiment (Fig. 1b), the Arctic Ocean experiences great sea ice loss, especially in the Barents-Kara Seas and Beaufort-Chukchi Seas (not shown), with local surface temperatures warmer than $-5^{\circ} \mathrm{C}$ in these areas, and a forcing temperature of $0^{\circ} \mathrm{C}$. In the ECP2290 experiment (Fig. 1c), the entire Arctic Ocean is almost ice free, with SSTs above $0^{\circ} \mathrm{C}$ almost everywhere, and a forcing temperature near $8^{\circ} \mathrm{C}$. Finally, in the SSTn $=20$ experiment (Fig. 1d), SSTs are essentially uniform at $20^{\circ} \mathrm{C}$ north of $45^{\circ} \mathrm{N}$, so the forcing temperature is also $20^{\circ} \mathrm{C}$.

The large warming of ocean and sea ice surface temperatures north of $45^{\circ} \mathrm{N}$ leads to a dramatic response of the boreal winter (DJF) temperature distribution over continental interiors. Figure 2 shows the winter mean 2-m temperature (left panels), the $1 \%$ lowest quantile of daily minimum temperature (center panels), and the standard deviation of daily mean temperature during DJF (right panels). The $1 \%$ lowest quantile of daily minimum temperature represents roughly the minimum temperature experienced in each winter, and thus relates to minimum-temperature tolerances of different species. Since the response over the continental interiors of Asia and Europe is similar to the response in North America, the following discussion mainly focuses on North America. In the PI experiment, the mean DJF temperature (Fig. 2a) over most of North America is below $0^{\circ} \mathrm{C}$, the mean temperature over the high latitudes reaches below $-30^{\circ} \mathrm{C}$, and the $1 \%$ lowest quantile (Fig. 2b) over the high latitudes reaches below $-45^{\circ} \mathrm{C}$. The PI standard deviation (Fig. 2c) over the high latitudes is around $10^{\circ} \mathrm{C}$. In our warmest scenario, shown in the SSTn $=20$ experiment, both the winter mean temperature (Fig. 2j) and the $1 \%$ lowest quantile (Fig. 2k) 

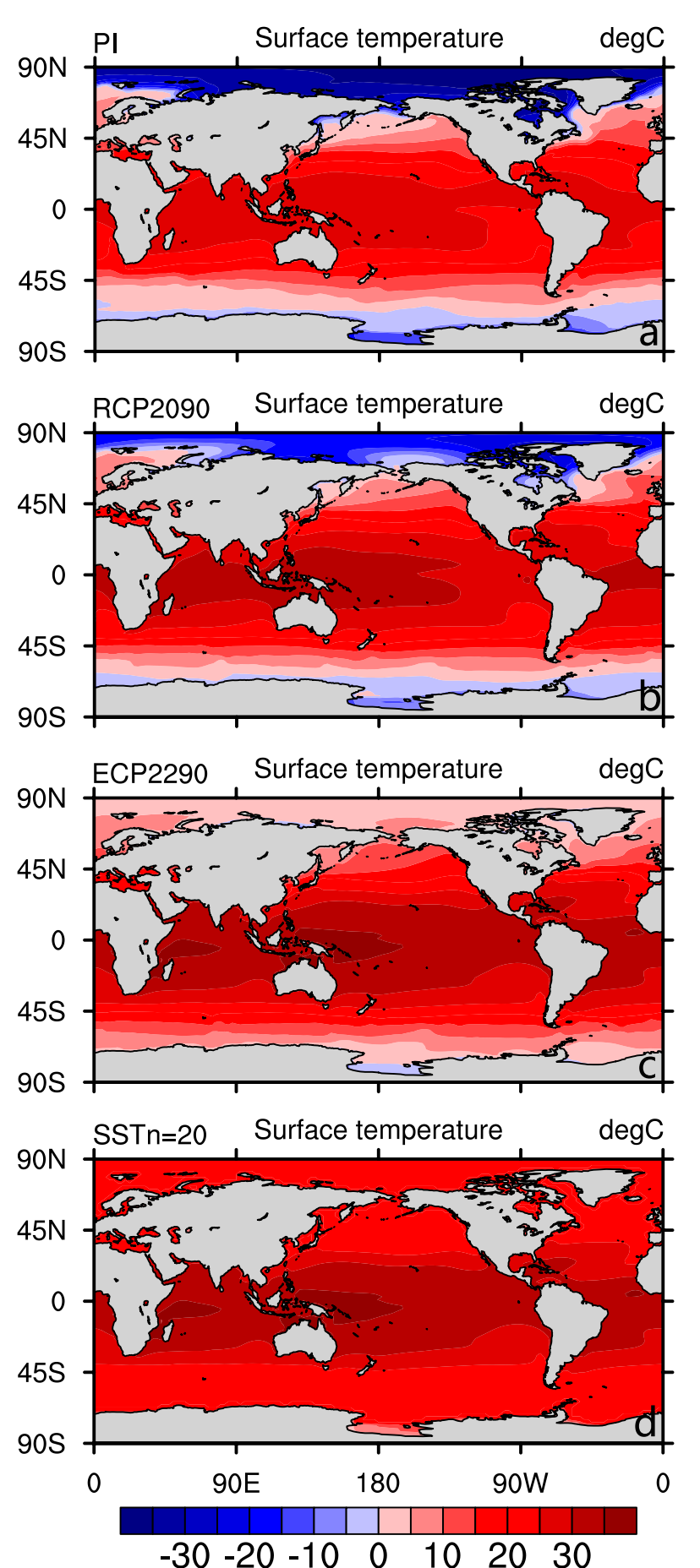

FIG. 1. Winter (DJF) mean surface temperature over the oceans (prescribed) and sea ice (where temperature is calculated): (a) PI, (b) RCP2090, (c) ECP2290, and (d) SSTn $=20$.

over the high latitudes increase dramatically (to around $10^{\circ}$ and $0^{\circ} \mathrm{C}$, respectively), while the standard deviation (Fig. 2l) decreases to below $4^{\circ} \mathrm{C}$. In our warmest simulation, SSTn $=20$, large areas in North America, north of $45^{\circ} \mathrm{N}$, would still occasionally experience freezing temperatures during winter. However, frost-intolerant flora and fauna may still survive, in most areas, based on the following criteria: for palms (Greenwood and Wing 1995), a cold month mean temperature greater than $5^{\circ} \mathrm{C}$ and a yearly minimum temperature greater than $-10^{\circ} \mathrm{C}$, and for crocodiles (Markwick 1994) a cold month mean temperature greater than $7^{\circ} \mathrm{C}$ and a cold month mean of daily minimum temperature greater than $1.5^{\circ} \mathrm{C}$. The location of fossil records of palms and crocodiles is nearly south of $60^{\circ} \mathrm{N}$ for palms and south of $55^{\circ} \mathrm{N}$ for crocodiles (Greenwood and Wing 1995; Markwick 1994). Plotting these criteria (not shown), we find that most of the area south of $60^{\circ} \mathrm{N}$ is warm enough for palms to survive, and most of area south of $55^{\circ} \mathrm{N}$ is warm enough for crocodiles to survive. Temperatures over most of interior Asia outside of the subtropics are not warm enough for palms and crocodiles to survive (not shown), although we expect this result might be altered by the differing continental positions and coastlines of the Eocene, especially including the possibility of extensive interior waterways and shallow seas in central Asia.

Figure 3a shows the winter mean 2-m temperature (red dots) and the $1 \%$ lowest quantile of winter $2-\mathrm{m}$ daily mean (orange) and daily minimum (blue) temperature, averaged over North America north of $45^{\circ} \mathrm{N}$, as function of the ocean forcing temperature. As the forcing temperature increases in these experiments from $-9^{\circ}$ to $20^{\circ} \mathrm{C}$, the average land temperature warms by about the same amount. However, the $1 \%$ lowest quantile of daily mean temperature increases by about $43^{\circ} \mathrm{C}$, nearly $50 \%$ more than the increase in the forcing temperature and in the winter mean continental temperature. A similar result, with an even stronger warming response, holds for the lowest $1 \%$ of daily minimum temperatures. This difference in the response of the mean and lowest quantiles is related to the rapid decrease of the standard deviation of the temperature (Fig. 3b, red dots).

The reduced variability in winter temperatures can also be demonstrated by the change of the probability density function (PDF) of winter 2-m temperature at one location in north-central Canada $\left(65^{\circ} \mathrm{N}, 100^{\circ} \mathrm{W}\right.$; Fig. 3c). As the PDF shifts to the warmer mean temperatures, it also becomes increasingly narrow, reflecting the decrease of the variance. Choosing another location or considering an average over a certain latitude band over high-latitude North America does not change the results qualitatively. This narrowing of the PDF makes the cold tail shift faster than the mean (it also makes the warm tail shift less than the mean, but that is not our focus in this paper). The difference between the $1 \%$ lowest quantile of winter 2 -m daily mean and daily minimum temperature (Fig. 3b, blue dots) remains nearly unchanged in the first few simulations 


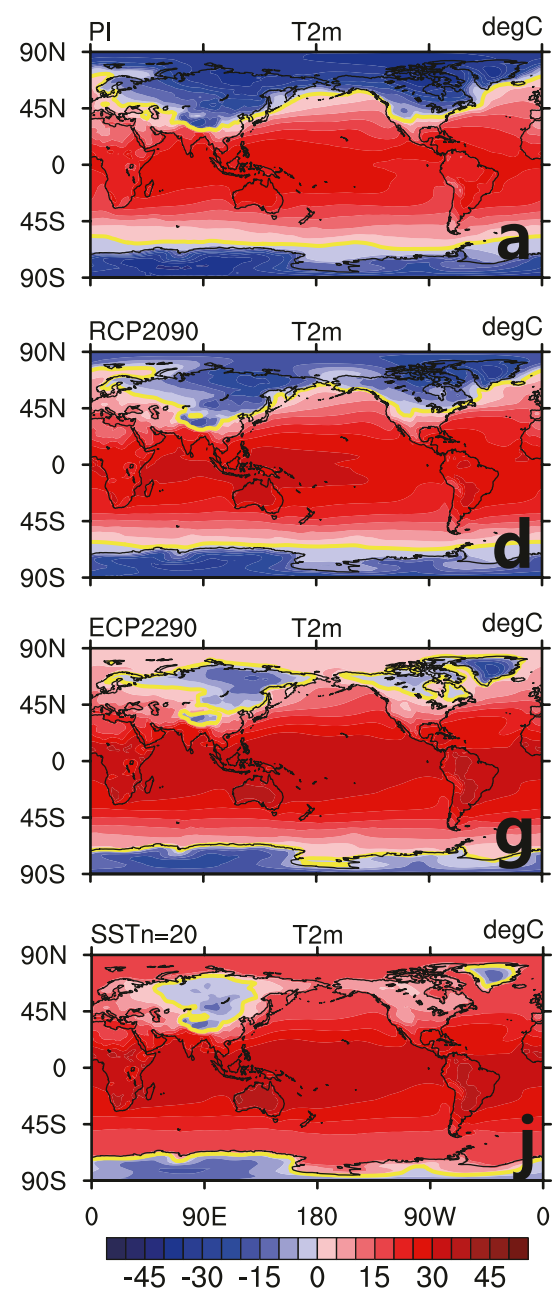


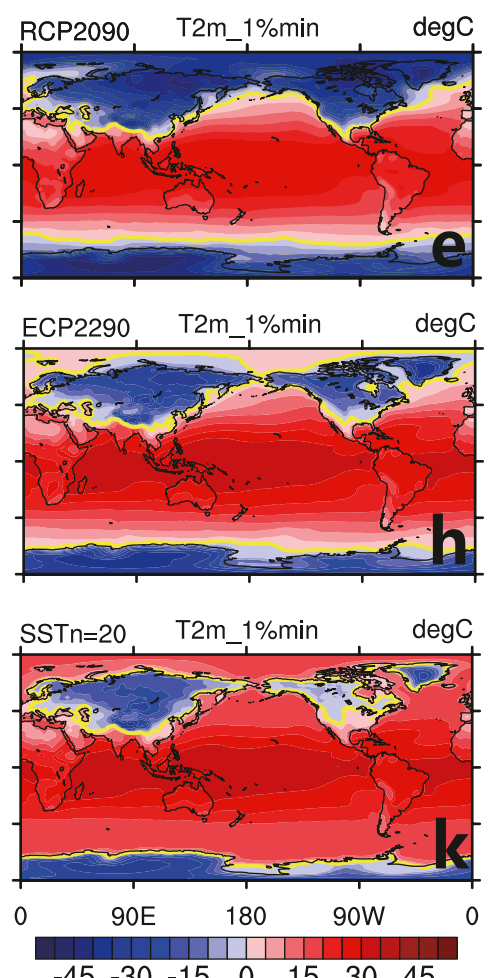

$\begin{array}{lllllll}-45 & -30 & -15 & 0 & 15 & 30 & 45\end{array}$
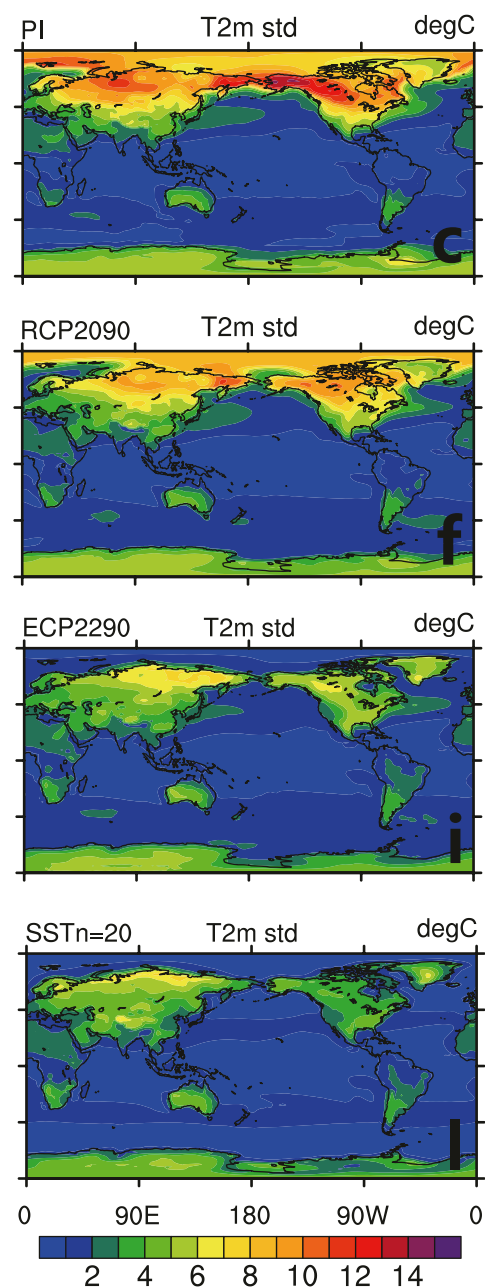

FIG. 2. Winter (DJF) (left) mean of 2-m daily mean temperature, (center) $1 \%$ lowest quantile of daily minimum temperature, and (right) standard deviation of 2-m daily mean temperature distribution for four experiments: (a)-(c), PI, (d)-(f) RCP2090, (g)-(i) ECP2290, and (j)-(l) SSTn $=20$. Thick yellow lines in the left and center columns represent the zero contour.

but then decreases significantly after the forcing temperature increases to $10^{\circ} \mathrm{C}$. This decrease is related to the suppression of surface radiative cooling on the coldest days, as will be seen below (section 3c). Figure 3d shows the corresponding PDFs of the net longwave (LW) radiation. The warmer simulations move toward zero net surface LW radiation at the surface, and these states are characterized by a near-unity low cloud fraction (not shown), consistent with the cloudy state of Stramler et al. (2011). The ECP2300 run in particular shows a sharp elimination of the warm temperature distribution tail near the freezing temperature (orange curve in Fig. 3c). This peak of the pdf near the freezing temperature also corresponds a state of near-zero net LW radiation (Fig. 3d) and thus a cloudy state.

We next examine the changes to the wintertime vertical temperature profile over land (Fig. 3e) at the same location $\left(65^{\circ} \mathrm{N}, 100^{\circ} \mathrm{W}\right)$. In the PI experiment, the vertical temperature profile shows a strong temperature inversion below $800 \mathrm{hPa}$, with a decrease from $-20^{\circ} \mathrm{C}$ at $800 \mathrm{hPa}$ to $-35^{\circ} \mathrm{C}$ at the surface. In our warmest scenario, the SSTn $=20$ experiment, this temperature inversion is effectively gone, and the temperature is nearly uniform below $900 \mathrm{hPa}$. This weakening of temperature inversion is a manifestation of surface-amplified warming, as seen by studies of simulated and observed Arctic warming (e.g., Collins et al. 2013; Kay et al. 2012; Pithan and Mauritsen 2014; Screen and Simmonds 2010), and is consistent with the studies of the suppression of Arctic air formation based on a Lagrangian column model (Cronin and Tziperman 2015; Cronin et al. 2017). Figure $3 \mathrm{f}$ shows temperature profiles during coldest $1 \%$ extremes for these runs. Even in the warmest run, the cold extremes show subfreezing temperature and a 

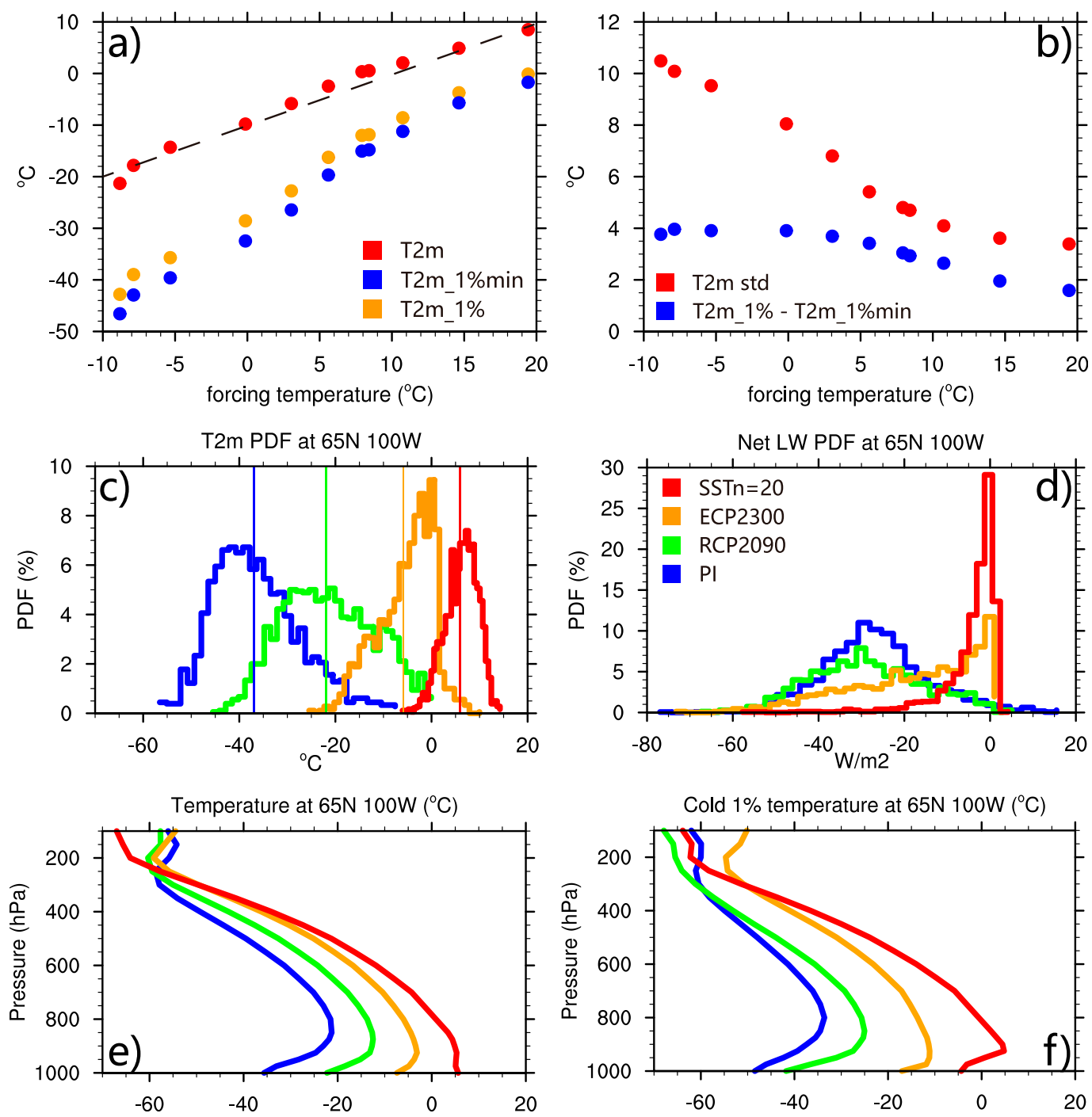

FIG. 3. (a) Winter (DJF) mean 2-m daily mean temperature (red) and winter $1 \%$ lowest quantile of the 2-m daily mean (orange) and daily minimum (blue) temperature, averaged over North America north of $45^{\circ} \mathrm{N}$, as a function of forcing temperature, which is defined as the averaged surface temperature over ocean and sea ice north of $45^{\circ} \mathrm{N}$. The dashed line represents a slope- 1 line where the 2-m temperature increases exactly as does the forcing temperature. (b) Winter standard deviation of 2-m daily mean temperature (red), and the difference between $1 \%$ lowest quantile of 2-m daily mean temperature and daily minimum temperature (blue) averaged over North America north of $45^{\circ} \mathrm{N}$, as a function of surface temperature over ocean and sea ice north of $45^{\circ} \mathrm{N}$. (c) Probability distribution of winter $2-\mathrm{m}$ temperature at location $65^{\circ} \mathrm{N}, 100^{\circ} \mathrm{W}$ for four experiments: PI (blue), RCP2090 (green), $\mathrm{ECP} 2290$ (orange), and SSTn $=20$ (red). Respectively, the mean values are $-37.0^{\circ},-21.9^{\circ},-5.9^{\circ}$, and $5.9^{\circ} \mathrm{C}$; the standard deviations are $9.1^{\circ}, 9.6^{\circ}, 5.8^{\circ}$, and $3.4^{\circ} \mathrm{C}$; the skewnesses are $0.61,0.15,-0.61$, and -0.41 ; and the kurtosis values are $0.19,-0.76,-0.16$, and -0.12 . (d) Histograms as in (c), but for net longwave radiation at the surface. (e) Winter mean vertical temperature profile at location $65^{\circ} \mathrm{N}, 100^{\circ} \mathrm{W}$ in four experiments: PI (blue), RCP2090 (green), ECP2290 (orange), and SSTn $=20$ (red). (f) As in (e), but for the coldest $1 \%$ of days.

near-surface inversion, although its vertical extent is smaller now.

\section{b. Changes in clouds}

As the climate warms, high-latitude land shifts from a radiatively clear boundary to a cloudy boundary layer state, as illustrated by a bivariate PDF of 2-m air temperature and low cloud fraction at the specific location $\left(65^{\circ} \mathrm{N}\right.$, $100^{\circ} \mathrm{W}$ ) discussed above (Fig. 4). In the PI run, most days have only scattered low clouds (fractions less than $20 \%$ ), and cold extremes nearly always occur under mostly clear skies, but many moderately cold days also occur under clear skies. This indicates that the absence of low clouds is necessary, but not sufficient, for an extreme 


\section{Bivariate PDF (\%)}
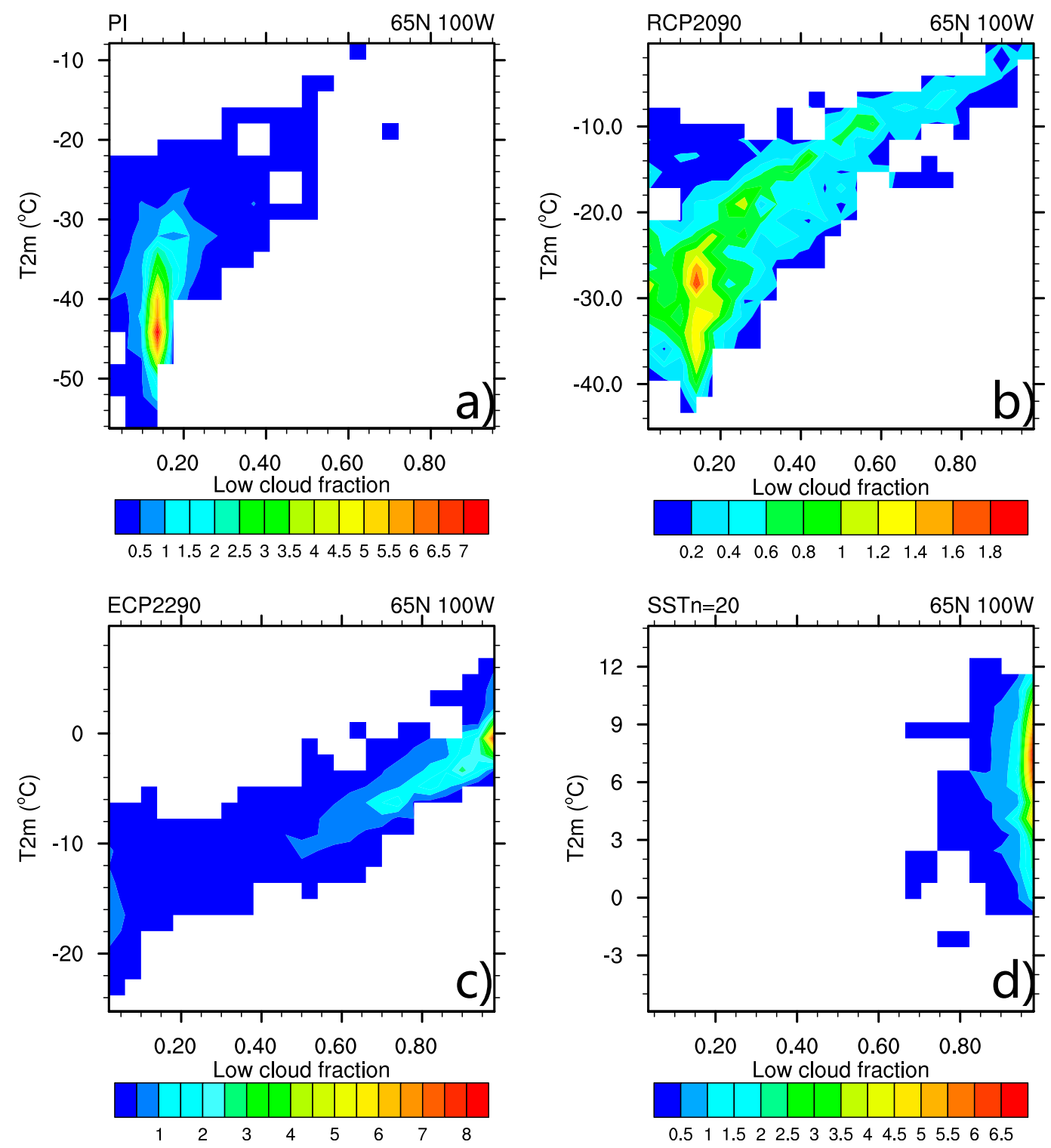

FIG. 4. Bivariate probability density function of low cloud fraction and 2-m temperature (T2m) for four experiments: (a) PI, (b) RCP2090, (c) ECP2290, and (d) SSTn $=20$.

cold event to occur. The warmer simulations show a gradual move toward a larger fraction of low-cloud cover, until at SSTn $=20$ nearly all days are overcast with low clouds. In a sense, the clear boundary layer state of Stramler et al. (2011) disappears with sufficient ocean warming. The bivariate PDF in Fig. $4 \mathrm{~d}$ shows that even the cold extremes in the warmest run $(\operatorname{SSTn}=20)$ have a large fraction of low clouds, and at the same time the surface temperature does not go significantly below zero. For intermediate runs (RCP2290 and ECP2290) there is also a clearer relation between local low cloud cover and surface temperature, indicating that this low cloud cover is a significant factor in determining the local surface temperature.

To further explore how cloud properties and radiative effects over land respond to ocean warming, we first examine cloud radiative forcing at the surface as a function of the averaged ocean and sea ice temperature north of $45^{\circ} \mathrm{N}$. In this paper, cloud radiative forcing at the surface is defined as the difference between downward all-sky radiation and downward clear-sky radiation at the surface. Figure 5a shows longwave, shortwave, 

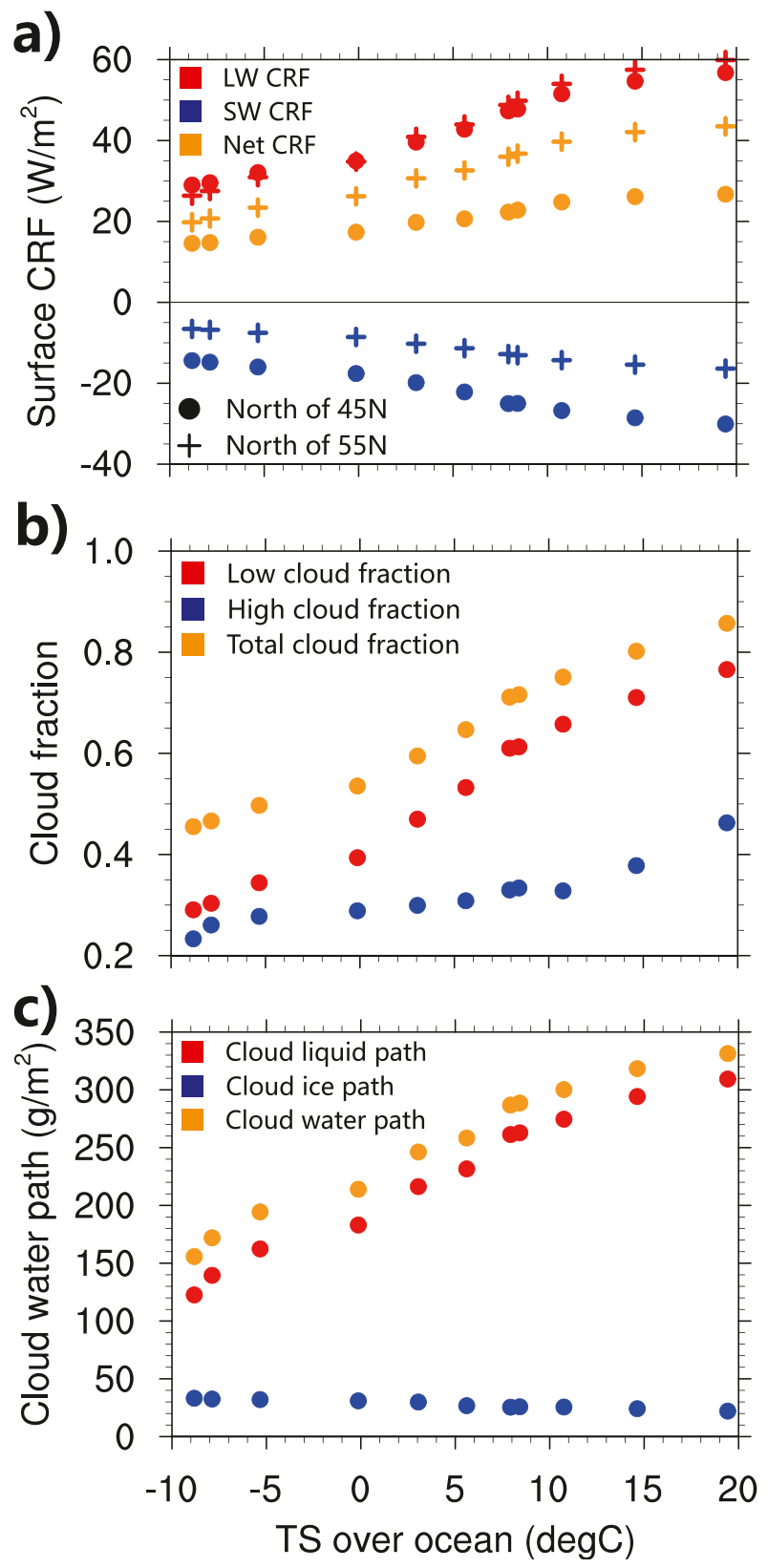

FIG. 5. Variables demonstrating the low-cloud warming mechanism, averaged over winter (DJF) and over North America north of $45^{\circ} \mathrm{N}$ (dots) and north of $55^{\circ} \mathrm{N}$ (crosses), as a function of surface temperature over ocean and sea ice north of $45^{\circ} \mathrm{N}$. (a) Longwave (red), shortwave (blue), and net (orange) cloud radiative forcing at the surface. (b) Low cloud fraction (red), high cloud fraction (blue), and total cloud fraction (orange). (c) Vertically integrated cloud liquid water path (red), ice path (blue), and total water path (orange).

and net (longwave plus shortwave) cloud radiative forcing at the surface (hereafter LWCRF, SWCRF, and NETCRF, respectively) averaged over North America north of $45^{\circ} \mathrm{N}$ and north of $55^{\circ} \mathrm{N}$. In the averages north of $45^{\circ} \mathrm{N}$, LWCRF almost doubles from 29 to $57 \mathrm{~W} \mathrm{~m}^{-2}$ from the coldest PI to the warmest SSTn $=20$ experiment. This increase suggests a robust cloud warming effect over high-latitude continental interiors. Although incoming solar SW radiation decreases to zero near the polar region, SWCRF becomes more negative as the surface forcing temperature is increased, partially compensating some of the increase in LWCRF over high latitudes. SWCRF decreases from $-14 \mathrm{~W} \mathrm{~m}^{-2}$ in the PI experiment to $-30 \mathrm{~W} \mathrm{~m}^{-2}$ in the $\mathrm{SSTn}=20$ experiment, such that NETCRF still nearly doubles from $15 \mathrm{~W} \mathrm{~m}^{-2}$ in PI to $27 \mathrm{~W} \mathrm{~m}^{-2}$ in the SSTn $=20$ experiment, albeit with a smaller change than LWCRF by itself. For averages north of $55^{\circ} \mathrm{N}$, LWCRF does not differ much from the average north of $45^{\circ} \mathrm{N}$. However, SWCRF becomes much weaker due to the smaller insolation at higher latitudes, leading to a larger increase in NETCRF, from $20 \mathrm{~W} \mathrm{~m}^{-2}$ in PI to $44 \mathrm{~W} \mathrm{~m}^{-2}$ in the SSTn $=20$ experiment.

The spatial pattern of LWCRF changes (Fig. 6, left panels) again shows large increases of LWCRF over North America. The increase is mostly north of $45^{\circ} \mathrm{N}$ and it is generally stronger at higher latitudes. The SWCRF change (Fig. 6, center panels) is weaker at higher latitudes, but SWCRF still decreases by $10 \mathrm{~W} \mathrm{~m}^{-2}$ near $60^{\circ} \mathrm{N}$ from the PI to the SSTn $=20$ experiment. The NETCRF change (Fig. 6, right panels) from the PI simulation shows warming at high latitudes and cooling at midlatitudes.

This meridional distribution of cloud radiative forcing is further illustrated in Fig. 7, which shows the change of zonally averaged cloud radiative forcing over land and sea ice, relative to the PI experiment. Between the middle and high latitudes, the NETCRF change shows a clear positive meridional gradient (Fig. 7c), due both to the increase of LWCRF (Fig. 7a) at high latitudes and the decrease of SWCRF (toward more negative values; Fig. 7b) at midlatitudes. Between $45^{\circ}$ and $65^{\circ} \mathrm{N}$, the meridional gradient of NETCRF change (relative to PI) increases from $0.6 \mathrm{~W} \mathrm{~m}^{-2}$ per degree latitude in the $\mathrm{RCP} 2090$ experiment to $1.6 \mathrm{~W} \mathrm{~m}^{-2}$ per degree latitude in the SSTn $=20$ experiment. To put these numbers in context, the observed meridional gradient in zonalmean DJF net surface shortwave flux in the current climate is only $-2.5 \mathrm{~W} \mathrm{~m}^{-2}$ per degree of latitude from $45^{\circ}$ to $65^{\circ} \mathrm{N}$ (based on the CERES EBAF-Surface Ed4.0 dataset; Kato et al. 2018). Changes in the meridional gradient of net cloud forcing thus offset almost twothirds of the differential solar forcing of the surface energy budget over winter land, indicating that clouds could contribute to the reduced meridional surface temperature gradient over land. This leads us to speculate that cloud changes might also contribute to the decrease of winter temperature variance that results 

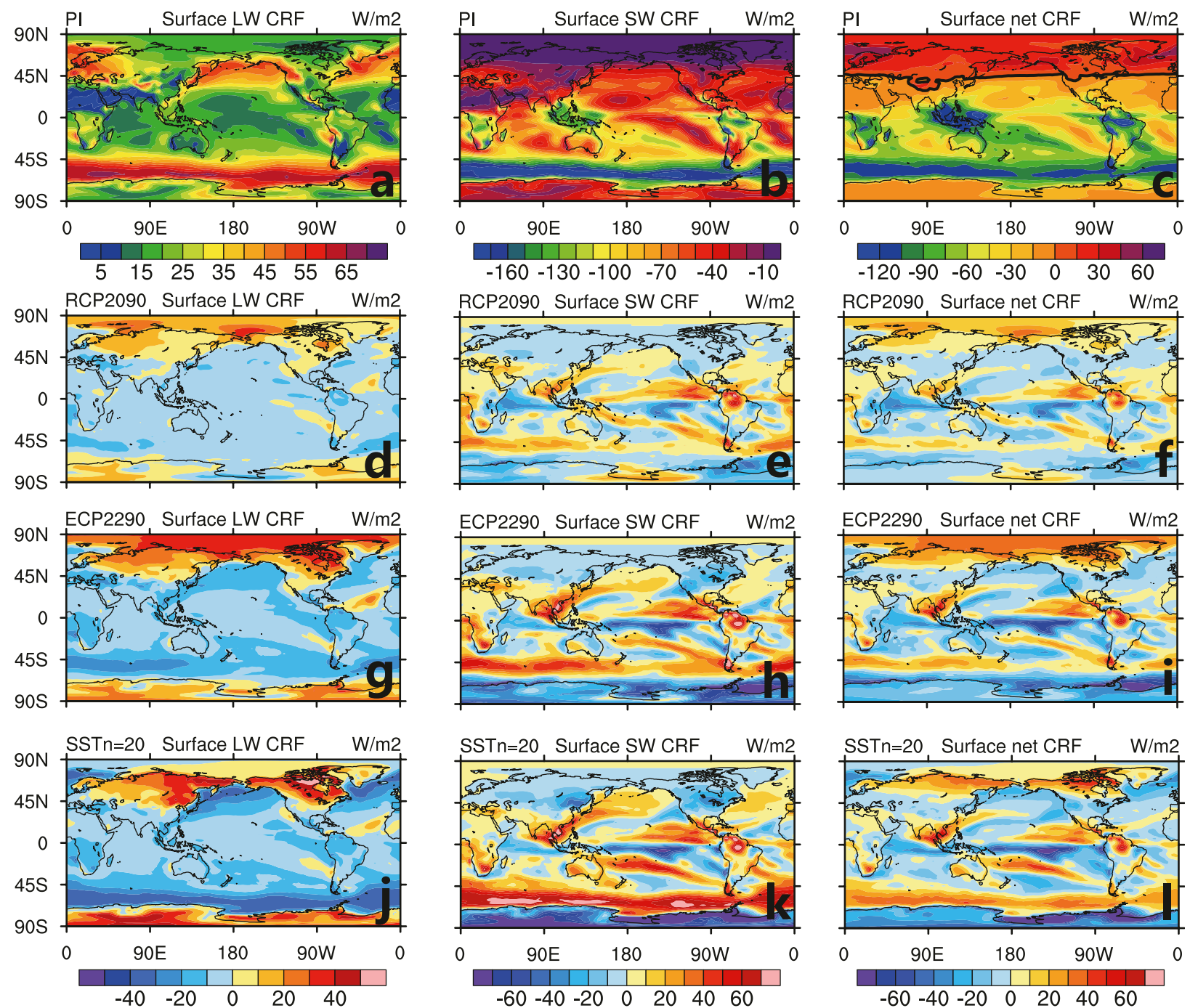

FIG. 6. Spatial pattern of winter (DJF) climatology of (left) longwave, (center) shortwave, and (right) net cloud radiative forcing at the surface in (a)-(c) experiment PI, and the change of these variables relative to PI in experiments (d)-(f) RCP2090, (g)-(i) ECP2290, and (j)-(1) SSTn $=20$. The thick black contour in Fig. 6c represents the zero contour.

from meridional exchanges of air masses (Screen 2014; Schneider et al. 2015), and thus to the greater warming of extreme cold events relative to winter mean temperatures. Verifying this speculation, however, would require additional analysis, and arguments about temperature variance based on meridional temperature gradients are complicated in the warmest simulations by a local reversal of the meridional temperature gradient along the Arctic coast of North America (e.g., Figs. 2g,j).

The cloud radiative forcing changes are explained by Fig. 5b, which shows the change of cloud fraction, averaged over North America north of $45^{\circ} \mathrm{N}$. From the PI to the SSTn $=20$ experiment, the total cloud fraction almost doubles from $46 \%$ to $86 \%$. The change in total cloud fraction is dominated by the change of low cloud fraction, which increases from $29 \%$ to $77 \%$. Here, low cloud fraction is defined as the cloud fraction below $700 \mathrm{hPa}$, and high cloud fraction is defined as the cloud fraction above $400 \mathrm{hPa}$. The change of LWCRF is closely related to the change of low cloud fraction, with a linear correlation of 0.99 between the areaaveraged LWCRF and low cloud fraction (North America north of $\left.45^{\circ} \mathrm{N}\right)$. The spatial pattern of the change of low cloud fraction (Fig. 8, center panels) is also similar to the change of LWCRF (Fig. 6, left panels), with the change over North America occurring mainly north of $45^{\circ} \mathrm{N}$. Figure $5 \mathrm{~b}$ also shows the change of high cloud fraction, which does not begin to increase significantly until the forcing temperature exceeds 



FIG. 7. The change of zonally averaged (a) longwave, (b) shortwave, and (c) net cloud radiative forcing at the surface, relative to PI in experiments RCP2090 (green lines), ECP2290 (orange lines), and SSTn $=20$ (red lines). The zonal averages are calculated over land and sea ice.

$10^{\circ} \mathrm{C}$. The increase in high clouds occurring over North America for forcing temperatures above $10^{\circ} \mathrm{C}$ seems to be related to an eastward advection of the high clouds forming over the North subpolar Pacific Ocean (Fig. 8, right panels).

In addition to the low cloud fraction increase, cloud water path also increases significantly (Fig. 5c). From the PI to the SSTn $=20$ experiment, the cloud liquid path more than doubles from 123 to $309 \mathrm{~g} \mathrm{~m}^{-2}$, while the cloud ice path decreases by a small amount. The spatial pattern of the change of the cloud liquid water path (Fig. 8, left panels) is also similar to the change of LWCRF (Fig. 6, left panels) and low cloud fraction (Fig. 8, center panels), with the change over North America occurring mainly north of $45^{\circ} \mathrm{N}$.

It is helpful to try and understand the reason for the layered cloud fraction changes between these simulations. In CAM4, a baseline layered cloud fraction $\bar{C}_{c}$ is calculated from the relative humidity $(\mathrm{RH})$ using $\bar{C}_{c}=(\mathrm{RH}-\mathrm{RH} \min )^{2} /(1-\mathrm{RH} \min )^{2}$, where $\mathrm{RH} \min$ is a threshold value below which no layered cloud forms. For low layered clouds (pressures greater than $750 \mathrm{hPa}$ ) RH $\min =0.91$ over ocean and $\mathrm{RH} \min =0.81$ over land. CAM4 also has a "freezedry" modification to the layered cloud fraction for cold conditions (Vavrus and Waliser 2008), which is a macrophysical change intended to represent the weaker turbulence and thus the reduced subgrid variability of highly stable atmospheric conditions typical of polar winter. This so-called freezedry modification is implemented as a reduction in the layered cloud fraction under very cold or dry conditions: $C_{c}=\bar{C}_{c} \times\{\max [0.15, \min (1, q / 3)]\}$, where $q$ is the specific humidity $\left(\mathrm{g} \mathrm{kg}^{-1}\right)$. When $q$ is below $0.45 \mathrm{~g} \mathrm{~kg}^{-1}, C_{c}=\bar{C}_{c} \times 0.15$; when $q$ is above $3 \mathrm{~g} \mathrm{~kg}^{-1}, \bar{C}_{c}$ is not modified; and when $q$ is between 0.45 and $3 \mathrm{~g} \mathrm{~kg}^{-1}$, $C_{c}=\bar{C}_{c} \times q / 3$. We find that the increase in low cloud fraction from the PI to ECP2290 simulations occurs mainly because warming causes specific humidity to increase enough that the freezedry modification is deactivated, while relative humidity actually decreases slightly. From the ECP2290 to the SSTn $=20$ simulations the specific humidity still increases, yet it is above $3 \mathrm{~g} \mathrm{~kg}^{-1}$, and low cloud fraction therefore increases because of the increase of relative humidity due to the dependence on $\mathrm{RH}$.

Related to the subgrid-scale physics that the freezedry modification is intended to represent, the mechanism of increasing turbulent mixing with warming was captured by the two-dimensional model of Cronin et al. (2017) and was argued to give greater cloud longevity than found by the single-column model of Cronin and Tziperman (2015). However, the main mechanisms responsible for greater cloud fraction with warming (via longer cloud persistence) in Cronin and Tziperman (2015) and Cronin et al. (2017) were argued to be the greater initial water vapor content of a warmer atmosphere and changes in cloud microphysical processes that lead to less efficient cloud water removal for warm liquid than for cold mixedphase clouds. Thus, the mechanisms of cloud fraction increase in this study differ somewhat from those found by previous work. 

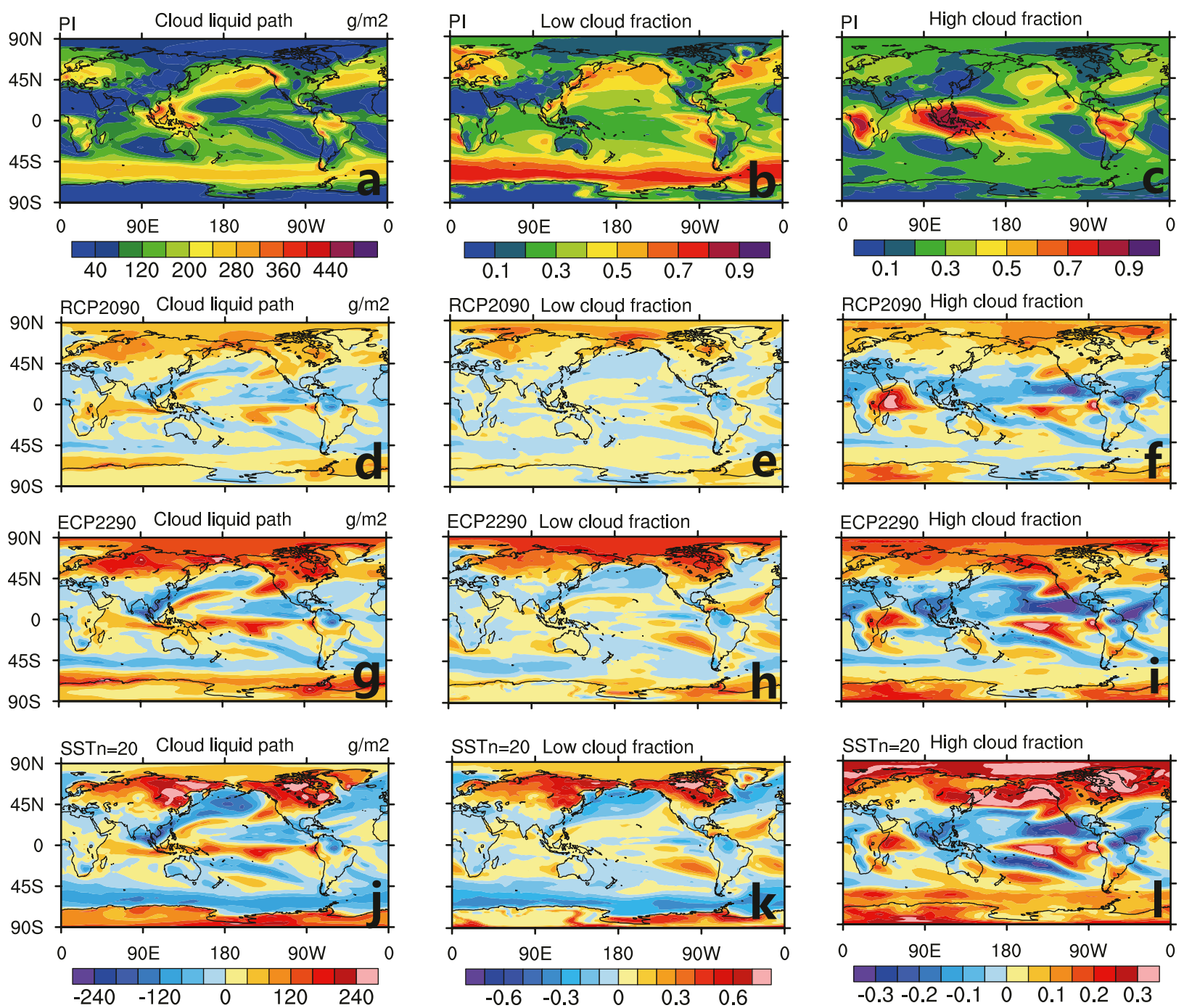

FIG. 8. Spatial patterns of winter (DJF) climatology of (left) cloud liquid water path, (center) low cloud fraction, and (right) high cloud fraction in (a)-(c) experiment PI, and the change of these variables relative to PI in experiments (d)-(f) RCP2090, (g)-(i) ECP2290, and (j)-(l) SSTn $=20$.

A similar low cloud warming effect also exists over the Arctic Ocean for experiments in which winter sea ice is not eliminated: in Fig. 6 (left panels), LWCRF significantly increases from the PI experiment to the ECP2290 experiment, with a consistent increase of the cloud liquid path and low cloud fraction (Fig. 8, left and center panels). However, for larger specified surface warming, where sea ice is eliminated, low clouds decrease as the SST is further increased. From the ECP2290 experiment to the SSTn $=20$ experiment, both low cloud fraction and cloud liquid path decrease over the Arctic, leading to a decrease of LWCRF there. This decrease of low cloud is related to wintertime convection, which produces more high clouds over the Arctic Ocean, and which in turn leads to a strong warming feedback over the Arctic, previously proposed as an explanation for high-latitude warmth during past warm climates and found to be present in future warming scenarios (Fig. 8, right panels; Abbot and Tziperman 2008a,b; Abbot et al. 2009b; Abbot and Tziperman 2009; Arnold et al. 2014). The liquid path of low clouds is higher than that of high convective clouds that may develop, and therefore the decrease of low cloud fraction also leads to the decrease in cloud liquid path.

Overall, the results of surface-enhanced warming, together with increased LWCRF, low cloud fraction, and liquid water path are broadly consistent with the mechanism of suppression of Arctic air formation by thicker and more extensive low liquid clouds studied by Cronin and Tziperman (2015) and Cronin et al. (2017). 
As demonstrated by the foregoing discussion of the reasons for changes in cloud fraction with warming in CAM4, however, similar clouds changes may be caused by different details of model parameterizations.

\section{c. Changes in the surface energy budget}

The changes in LWCRF are compared to changes in other terms of the surface energy balance for land points north of $45^{\circ} \mathrm{N}$ in Fig. 9. In the winter mean (Fig. 9a), between the coldest experiment (PI) and the warmest experiment $(\mathrm{SSTn}=20)$, downward clear-sky longwave radiation increases by about $120 \mathrm{~W} \mathrm{~m}^{-2}$, which is much larger than the increase in LWCRF of $25 \mathrm{~W} \mathrm{~m}^{-2}$. Upward longwave radiation from the surface increases slightly more than does the downward clear-sky longwave flux, and the downward turbulent heat flux to the surface and net shortwave radiation both decrease between the PI and SSTn $=20$ experiments, cooling the surface. The situation for extreme cold days (the $1 \%$ of daily mean temperature; Fig. 9b) is similar, but with larger increases in both upward surface longwave radiation (due to amplified warming of the coldest days) and downward clear-sky longwave radiation, and a similar magnitude of increase of LWCRF, but a more nonlinear onset once the forcing temperature rises above $5^{\circ}-10^{\circ} \mathrm{C}$. This nonlinear dependence of cloud fraction and LWCRF on the forcing temperature is similar to the dependence of these quantities on the initial 2-m air temperature in the cloud-resolving simulations of Cronin et al. (2017) but this resemblance may be coincidental. One explanation, particularly for extreme cold days, is that this nonlinear increase of low cloud fraction is related to both the delayed deactivation of the freezedry modification with warming and the nonmonotonic change of low-level relative humidity (decrease from RCP2090 to ECP2290 and increase from ECP2290 to SSTn = 20; not shown). It is also possible that as the Arctic Ocean becomes warmer than northern Canada, all air masses passing over North America start out relatively warm and moist, and thus form clouds as they cool over the continent. Either way, the increase in cloud fraction even on very cold days is consistent with the disappearance of the clear boundary layer state for very warm SSTs (Fig. 4d). Looking at land points north of $55^{\circ} \mathrm{N}$ rather than north of $45^{\circ} \mathrm{N}$ (not shown) gives a similar picture, with a somewhat larger role for LWCRF relative to the clear-sky radiation.

Following Gong et al. (2017), one can decompose changes in surface temperature as a sum of energy flux changes divided by a surface Planck feedback of about $4 \mathrm{~W} \mathrm{~m}^{-2} \mathrm{~K}^{-1}$ (or increase in longwave flux per unit increase in surface temperature, $4 \sigma T_{0}^{3}$, where $T_{0}$ is a reference surface temperature about which upward emission is
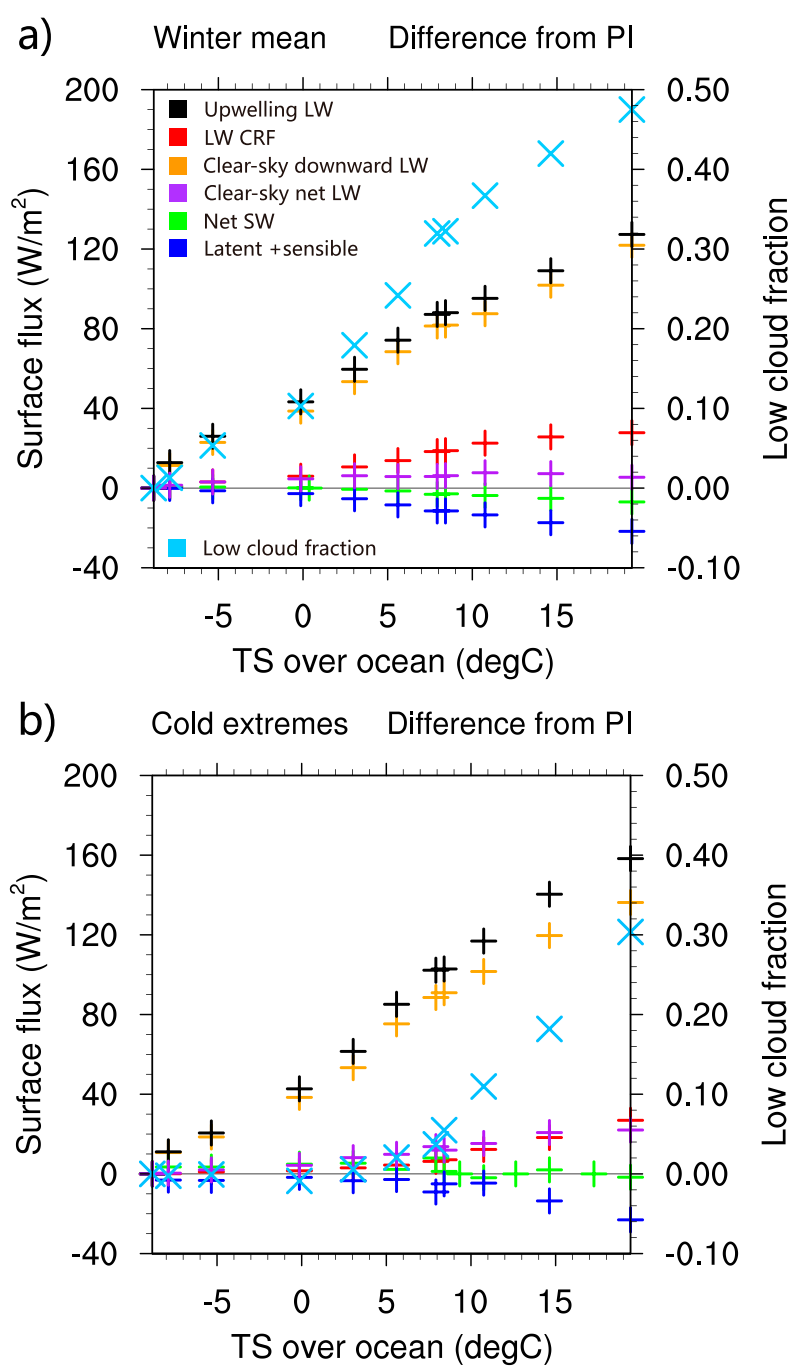

FIG. 9. (a) The winter-mean surface energy fluxes averaged at each grid point and then averaged over North America north of $45^{\circ} \mathrm{N}$, as a function of forcing temperature, which is defined as winter-mean surface temperature averaged over ocean and sea ice north of $45^{\circ} \mathrm{N}$, shown as the difference from PI; "+ " signs denote LW CRF (red), upward LW (black), downward clear-sky LW (orange), net clear-sky LW (purple), net SW (green), latent and sensible (blue). For upward LW and net clear-sky LW, upward fluxes are defined as positive, while for other terms downward fluxes are positive. The " $\times$ " symbols denote low cloud fraction, again differences from PI. (b) As in (a), but for the coldest $1 \%$ of days.

linearized). Applying this decomposition to the results shown in Fig. 9 suggests that land surface warming is caused by the greater downward longwave emission from the clear sky [as found by Gong et al. (2017) in historical trends]. This is in turn mostly a result of increasing temperature and moisture of the lower troposphere and not due to increases in carbon dioxide concentration (changes in clear-sky downward LW far exceed the surface $\mathrm{CO}_{2}$ radiative forcing). This interpretation seems reasonable: 
the dominant cause of land surface warming is greater clearsky downward longwave radiation, caused by warmer and moister air masses, which are maintained by warmer SSTs and advected over land. For three reasons, though, we believe that clouds play a larger role than this simple linear energy balance decomposition would suggest.

First, increases in clear-sky longwave fluxes primarily act to warm land temperatures at nearly the same rate as ocean temperatures in the winter mean, and with a smaller amplification factor than simulated for the cold extremes-so if we are concerned with the amplification of land warming relative to ocean, or the land-ocean warming contrast, cloud forcing changes become much more important. To estimate the warming that arises from the modeled clear-sky downward longwave flux changes between PI and SSTn $=20$, the flux changes of $120 \mathrm{~W} \mathrm{~m}^{-2}$ (winter mean; Fig. 9a) and $140 \mathrm{~W} \mathrm{~m}^{-2}$ (cold extremes; Fig. 9b) can be divided by surface Planck feedbacks corresponding to $T_{0}=0^{\circ} \mathrm{C}$ (winter mean for a forcing temperature of $5^{\circ} \mathrm{C}$; Fig. 3a) and $T_{0}=-20^{\circ} \mathrm{C}$ (cold extremes for a forcing temperature of $5^{\circ} \mathrm{C}$; Fig. 3a). This calculation gives warming estimates of $28^{\circ} \mathrm{C}$ for the winter mean and $38^{\circ} \mathrm{C}$ for the cold extremes as arising from the clear-sky downward longwave radiation. Although these estimates do account for the vast majority of the simulated temperature changes, if the warming effects of cloud changes were neglected, one could argue following Gong et al. (2017) that the land surface would then be expected to warm less in the winter mean than the mid- and high-latitude oceans, as a result of the reduction in the downward turbulent heat fluxes (Fig. 9). Neglecting the cloud forcing as unimportant could thus change the sign of the winter land-ocean warming contrast, which is of central importance in both our understanding of the equable climate problem and in the impacts of future climate change.

Second, low cloud fraction and LWCRF (Fig. 9) exhibit similar nonlinear trends to those seen in the difference between the $1 \%$ lowest quantile of winter $2-\mathrm{m}$ daily mean and daily minimum temperature (Fig. 3b, blue dots), which remains almost unchanged from the PI to the RCP2090 experiment but quickly decreases after the ocean forcing temperature is above $10^{\circ} \mathrm{C}$. The similarity suggests that the increasing low clouds, with the associated suppression of surface radiative cooling, partly contribute to the reduced diurnal temperature variation in extreme cold days of very warm climates. Note that we cannot analyze the daily minimum temperatures analogously to the winter mean and coldest $1 \%$ of days because we do not have separate data from snapshots of daily minimum temperatures.

Third, and most importantly, we believe that the approach of attributing changes in surface temperature to changes in individual energy fluxes is potentially misleading, because the clear-sky radiation, CRF, and turbulent fluxes are all part of a coupled boundary layer-surface system, making an additive decomposition ambiguous. If cloud radiative forcing were removed, the boundary layer and surface would cool and the near-surface air would become more stable, leading to a smaller clearsky downward radiative flux, and likely a larger turbulent heat flux into the surface. It is tempting to ignore the contribution to downward longwave radiation by the boundary layer, especially in the Arctic where it is so cold and dry, but even the lowest $200 \mathrm{~m}$ of the clear-sky subarctic atmosphere in winter of the present climate has a surprisingly large broad-band longwave emissivity of around 0.35 . Changes in boundary layer temperature will thus be associated with changes in downward clearsky longwave radiation, but such changes should not be thought of as a forcing of the surface energy balance that is independent from the surface temperature or low cloud properties; part of a change in clear-sky downward longwave radiation could in fact be caused by clouds. At present, we lack a good way to untangle these coupled influences on the Arctic surface energy budget and boundary layer state, so we believe it is most prudent to refrain from trying to be too precise with attribution statements about the causes of surface warming.

\section{Summary and limitations}

We used the Community Atmosphere Model, version 4 , with a prescribed sea surface temperature to study the effect of ocean warming on continental climate. We prescribed a range of SST warming scenarios, from preindustrial to an SST that is no colder than $20^{\circ} \mathrm{C}$, and our analysis focused in particular on cold extremes, as represented by the $1 \%$ lowest quantile of winter temperature over continents. The motivation is twofold: first, evidence of frost-intolerant species surviving in northern North America during equable climates (e.g., Greenwood and Wing 1995; Markwick 1998); second, the surface-enhanced high-latitude warming seen in both future model predictions and in observed trends over the past few decades (e.g., Collins et al. 2013; Screen and Simmonds 2010).

We find that as SSTs increase, so does the surface temperature over North America and Eurasia. While the averaged winter temperature increases by a similar amount to that of the prescribed ocean warming north of $45^{\circ} \mathrm{N}$, extreme cold events warm by as much as $50 \%$ more. We showed that longwave cloud radiative forcing (LWCRF) over North America north of $45^{\circ} \mathrm{N}$ increases by about $0.8 \mathrm{~W} \mathrm{~m}^{-2}$ per degree of ocean warming, and 
the meridional gradient of the net cloud radiative forcing favors high-latitude warming but midlatitude cooling over land as the ocean warms. The warming over North America is also found to coincide with a near-disappearance of the cold and clear boundary layer state of Stramler et al. (2011) in parts of the Arctic, consistent with the mechanism of the suppression of Arctic air formation in warm climates proposed by Cronin and Tziperman (2015). Cloud fraction in CAM, however, increases for reasons related to a parameterization of cloud macrophysics, which differs from the hypotheses of Cronin and Tziperman (2015) and Cronin et al. (2017) about thermodynamic and microphysical reasons for greater cloud longevity and thus cloud fraction in warm climates. Overall, our results here are broadly consistent with the picture of cloudier high-latitude continents with less severe cold extremes in warmer climates, but some of the key details differ in a $3 \mathrm{D}$ GCM as compared to previous idealized Lagrangian air mass studies (Cronin and Tziperman 2015; Cronin et al. 2017).

From a surface energy balance perspective, the increases in downward clear-sky longwave radiation dominate increases in longwave cloud radiative forcing, as found by Gong et al. (2017). We argue, however, that this does not minimize the importance of clouds, because these increases primarily allow land warming to keep pace with ocean warming, and because an additive attribution of warming to changes in different surface energy balance terms cannot account for the coupling among clouds, surface temperature, boundary layer temperature, and surface energy fluxes.

Since we use a full GCM, it is difficult to test the relative importance of specific mechanisms, including but not limited to low-cloud changes, by removing them entirely, because the basic state of the model is often strongly altered by such mechanism denial. For instance, Cronin and Tziperman (2015) and Cronin et al. (2017) tested the importance of the low-cloud warming mechanism by removing cloud-radiation interactions altogether and looking at the land surface temperature response to varied SSTs with and without cloudradiation interactions. However, in the GCM used here, removing cloud-radiation interactions dramatically alters the winter mean surface climate over land and sea ice, cooling preindustrial-climate 2-m air temperatures over high-latitude North America, Eurasia, and the Arctic Ocean by about $10^{\circ} \mathrm{C}$ (not shown). Similarly, snow albedo feedbacks might be important for amplifying warming over land, but altering the snow albedo feedback would also change the preindustrial climate markedly. We thus rely on the more detailed understanding of the low-cloud response that was possible in the above column studies, while the current study is meant to assure that the extreme idealizations used in those studies did not eliminate processes that would change their conclusions.

A further limitation of this work is that our results regarding changes in cloud properties are likely sensitive to the parameterizations of cloud microphysics in CAM4, and mixed-phase stratus cloud at high latitudes are a particularly difficult type of cloud for models to represent accurately (e.g., Pithan et al. 2014; McCoy et al. 2015; Pithan et al. 2016). Again, Cronin and Tziperman (2015) and Cronin et al. (2017) studied this sensitivity and found a similar response with different microphysics schemes. Yet the sensitivity of low clouds to SST could be quite different in a GCM, particularly considering the previously noted impacts of the cloud macrophysics scheme in CAM4.

While the model we used was of realistic geometry, our approach was idealized and process-oriented in that we prescribed a large range of SST perturbations in order to study the model in a broad parameter regime. While we are able to propose a mechanism for the enhanced continental warming, it relies on a strong imposed SST warming that is prescribed here, and whose mechanism we did not address.

This study is relevant both to the equable climate problem and to the lapse-rate feedback in future climate simulations. Our results, together with the convective cloud feedback over the Arctic studied by Abbot and Tziperman (2008a,b), Abbot et al. (2009b), Abbot and Tziperman (2009), and Arnold et al. (2014), indicate that clouds can lead to strong positive feedbacks over both high-latitude ocean and continents in a warmer climate.

Acknowledgments. We thank three anonymous reviewers for their most helpful suggestions. This work has been supported by the National Natural Science Foundation of China under Grants 41530423 and 41761144072 (ZH), and by the Harvard Climate Change solutions fund, Harvard Global Institute, NSF P2C2 Program Grant OCE-1602864, and the NSF Climate Dynamics program Grant AGS-1622985 (ET) and AGS-1623218 (TWC). ET thanks the Weizmann Institute for its hospitality during parts of this work.

\section{REFERENCES}

Abbot, D. S., and E. Tziperman, 2008a: A high latitude convective cloud feedback and equable climates. Quart. J. Roy. Meteor. Soc., 134, 165-185, https://doi.org/10.1002/qj.211.

$\longrightarrow$, and $-2008 \mathrm{~b}$ : Sea ice, high-latitude convection, and equable climates. Geophys. Res. Lett., 35, L03702, https://oi.org/ 10.1029/2007GL032286.

- and - 2009: Controls on the activation and strength of a high-latitude convective cloud feedback. J. Atmos. Sci., 66, 519-529, https://doi.org/10.1175/2008JAS2840.1. 
—, M. Huber, G. Bousquet, and C. C. Walker, 2009a: High- $\mathrm{CO}_{2}$ cloud radiative forcing feedback over both land and ocean in a global climate model. Geophys. Res. Lett., 36, L05702, https:// doi.org/10.1029/2008GL036703.

_ C. Walker, and E. Tziperman, 2009b: Can a convective cloud feedback help to eliminate winter sea ice at high $\mathrm{CO}_{2}$ concentrations? J. Climate, 22, 5719-5731, https://doi.org/10.1175/ 2009JCLI2854.1.

Alexeev, V. A., and C. H. Jackson, 2013: Polar amplification: Is atmospheric heat transport important? Climate Dyn., 41, 533547, https://doi.org/10.1007/s00382-012-1601-z.

Arnold, N., M. Branson, M. A. Burt, D. S. Abbot, Z. Kuang, D. A. Randall, and E. Tziperman, 2014: Effects of explicit atmospheric convection at high $\mathrm{CO}_{2}$. Proc. Natl. Acad. Sci. USA, 111, $10943-10948$, https://doi.org/10.1073/pnas.1407175111.

Cohen, J., and Coauthors, 2014: Recent Arctic amplification and extreme mid-latitude weather. Nat. Geosci., 7, 627-637, https:// doi.org/10.1038/ngeo2234.

Collins, M., and Coauthors, 2013: Long-term climate change: Projections, commitments and irreversibility. Climate Change 2013: The Physical Science Basis. T. F. Stocker et al., Eds., Cambridge University Press, 1029-1136.

Cronin, T. W., and E. Tziperman, 2015: Low clouds suppress Arctic air formation and amplify high-latitude continental winter warming. Proc. Natl. Acad. Sci. USA, 112, 11 490-11 495, https:// doi.org/10.1073/pnas.1510937112.

- , H. Li, and E. Tziperman, 2017: Suppression of Arctic air formation with climate warming: Investigation with a twodimensional cloud-resolving model. J. Atmos. Sci., 74, 27172736, https://doi.org/10.1175/JAS-D-16-0193.1.

Curry, J., 1983: On the formation of continental polar air. J. Atmos. Sci., 40, 2278-2292, https://doi.org/10.1175/1520-0469(1983)040<2278: $\mathrm{OTFOCP}>2.0 . \mathrm{CO} ; 2$.

Emanuel, K., 2002: A simple model of multiple climate regimes. J. Geophys. Res., 107, 4077, https://doi.org/10.1029/2001JD001002.

Farrell, B. F., 1990: Equable climate dynamics. J. Atmos. Sci., 47, 2986-2995, https://doi.org/10.1175/1520-0469(1990)047<2986: $\mathrm{ECD}>2.0 . \mathrm{CO} ; 2$.

Gao, Y., L. R. Leung, J. Lu, and G. Masato, 2015: Persistent cold air outbreaks over North America in a warming climate. Environ. Res. Lett., 10, 044001, https://doi.org/10.1088/1748-9326/10/4/ 044001.

Gent, P. R., and Coauthors, 2011: The Community Climate System Model version 4. J. Climate, 24, 4973-4991, https://doi.org/ 10.1175/2011JCLI4083.1.

Gong, T., S. Feldstein, and S. Lee, 2017: The role of downward infrared radiation in the recent Arctic winter warming trend. J. Climate, 30, 4937-4949, https://doi.org/10.1175/ JCLI-D-16-0180.1.

Greenwood, D. R., and S. L. Wing, 1995: Eocene continental climates and latitudinal temperature gradients. Geology, $\mathbf{2 3}$ 1044-1048, https://doi.org/10.1130/0091-7613(1995)023<1044: ECCALT $>2.3 . \mathrm{CO} ; 2$.

Huber, M., and R. Caballero, 2011: The early Eocene equable climate problem revisited. Climate Past, 7, 603-633, https:// doi.org/10.5194/cp-7-603-2011.

Hunke, E., and W. Lipscomb, 2008: CICE: The Los Alamos Sea Ice Model user's manual, version 4. Los Alamos National Laboratory Tech. Rep. LA-CC-06-012, 16 pp.

Kato, S., and Coauthors, 2018: Surface irradiances of edition 4.0 Clouds and the Earth's Radiant Energy System (CERES) Energy Balanced and Filled (EBAF) data product. J. Climate, 31, 4501-4527, https://doi.org/10.1175/JCLI-D-17-0523.1.
Kay, J. E., M. M. Holland, C. M. Bitz, E. Blanchard-Wrigglesworth, A. Gettelman, A. Conley, and D. Bailey, 2012: The influence of local feedbacks and northward heat transport on the equilibrium Arctic climate response to increased greenhouse gas forcing. J. Climate, 25, 5433-5450, https://doi.org/10.1175/ JCLI-D-11-00622.1.

Kirk-Davidoff, D. B., D. P. Schrag, and J. G. Anderson, 2002: On the feedback of stratospheric clouds on polar climate. Geophys. Res. Lett., 29, 1556, https://doi.org/10.1029/2002GL014659.

Korty, R. L., and K. A. Emanuel, 2007: The dynamic response of the winter stratosphere to an equable climate surface temperature gradient. J. Climate, 20, 5213-5228, https://doi.org/ 10.1175/2007JCLI1556.1.

—_ — - and J. R. Scott, 2008: Tropical cyclone-induced upper-ocean mixing and climate: Application to equable climates. J. Climate, 21, 638-654, https://doi.org/10.1175/ 2007JCLI1659.1.

Lawrence, D. M., and Coauthors, 2011: Parameterization improvements and functional and structural advances in version 4 of the Community Land Model. J. Adv. Model. Earth Syst., 3, M03001, https://doi.org/10.1029/2011MS00045.

Markwick, P. J., 1994: "Equability," continentality, and tertiary "climate": The crocodilian perspective. Geology, 22, 613-616, https:// doi.org/10.1130/0091-7613(1994)022<0613:ECATCT>2.3.CO;2. , 1998: Fossil crocodilians as indicators of late Cretaceous and Cenozoic climates: Implications for using palaeontological data in reconstructing palaeoclimate. Palaeogeogr. Palaeoclimatol. Palaeoecol., 137, 205-271, https://doi.org/10.1016/ S0031-0182(97)00108-9.

McCoy, D. T., D. L. Hartmann, M. D. Zelinka, P. Ceppi, and D. P. Grosvenor, 2015: Mixed-phase cloud physics and Southern Ocean cloud feedback in climate models. J. Geophys. Res., 120, 9539-9554, https://doi.org/10.1002/2015JD023603.

Neale, R., and Coauthors, 2010: Description of the NCAR Community Atmosphere Model (CAM 4.0). NCAR Tech. Note NCAR/TN-485+STR, 212 pp., www.cesm.ucar.edu/models/ ccsm4.0/cam/docs/description/cam4_desc.pdf.

Pithan, F., and T. Mauritsen, 2014: Arctic amplification dominated by temperature feedbacks in contemporary climate models. Nat. Geosci., 7, 181-184, https://doi.org/10.1038/ngeo2071.

_ B. Medeiros, and T. Mauritsen, 2014: Mixed-phase clouds cause climate model biases in Arctic wintertime temperature inversions. Climate Dyn., 43, 289-303, https://doi.org/10.1007/ s00382-013-1964-9.

_ - and Coauthors, 2016: Select strengths and biases of models in representing the Arctic winter boundary layer over sea ice: The Larcform 1 single column model intercomparison. J. Adv. Model. Earth Syst., 8, 1345-1357, https://doi.org/10.1002/2016MS000630.

Riahi, K., A. Grübler, and N. Nakicenovic, 2007: Scenarios of longterm socio-economic and environmental development under climate stabilization. Technol. Forecast. Soc. Change, 74, 887935, https://doi.org/10.1016/j.techfore.2006.05.026.

Schneider, T., T. Bischoff, and H. Płotka, 2015: Physics of changes in synoptic midlatitude temperature variability. J. Climate, $\mathbf{2 8}$, 2312-2331, https://doi.org/10.1175/JCLI-D-14-00632.1.

Screen, J. A., 2014: Arctic amplification decreases temperature variance in northern mid- to high-latitudes. Nat. Climate Change, 4, 577-582, https://doi.org/10.1038/nclimate2268.

— , and I. Simmonds, 2010: The central role of diminishing sea ice in recent Arctic temperature amplification. Nature, 464, 1334 1337, https://doi.org/10.1038/nature09051.

, C. Deser, and L. Sun, 2015: Reduced risk of North American cold extremes due to continued Arctic sea ice loss. Bull. 
Amer. Meteor. Soc., 96, 1489-1503, https://doi.org/10.1175/ BAMS-D-14-00185.1.

Sloan, L. C., J. C. G. Walker, T. C. Moore, D. K. Rea, and J. C. Zachos, 1992: Possible methane-induced polar warming in the early Eocene. Nature, 357, 320-322, https://doi.org/10.1038/357320a0.

Stramler, K., A. D. D. Genio, and W. B. Rossow, 2011: Synoptically driven Arctic winter states. J. Climate, 24, 1747-1762, https:// doi.org/10.1175/2010JCLI3817.1.

van Vuuren, D. P., and Coauthors, 2011: The representative concentration pathways: An overview. Climatic Change, 109, 5-31, https:// doi.org/10.1007/s10584-011-0148-z.
Vavrus, S., and D. Waliser, 2008: An improved parameterization for simulating Arctic cloud amount in the CCSM3 climate model. J. Climate, 21, 5673-5687, https://doi.org/10.1175/ 2008JCLI2299.1.

_ J. Walsh, W. Chapman, and D. Portis, 2006: The behavior of extreme cold air outbreaks under greenhouse warming. Int. J. Climatol., 26, 1133-1147, https://doi.org/10.1002/joc.1301.

Wing, S. L., and D. R. Greenwood, 1993: Fossils and fossil climate: The case for equable continental interiors in the Eocene. Philos. Trans. Roy. Soc. London, 341, 243-252, https://doi.org/ 10.1098/rstb.1993.0109. 